\title{
Personal values: A perceptual lens for investigating Spousal Perception of Marital Conflict among Ghanaian dual career couples
}

\author{
Linda Adzo Elorm Tormeti ${ }^{1}$, Roseline Mercy Abotsi ${ }^{2}$ \\ ${ }^{1}$ Registry, Accra Polytechnic, Accra, Ghana \\ ${ }^{2}$ School of Engineering, Accra Polytechnic, Accra, Ghana
}

Email address:

tjelorm@yahoo.com (L. A. E. Tormeti), roselinearm@yahoo.co.uk (R. M. Abotsi)

\section{To cite this article:}

Linda Adzo Elorm Tormeti, Roseline Mercy Abotsi. Personal Values: A Perceptual Lens for Investigating Spousal Perception of Marital Conflict among Ghanaian Dual Career Couples. American Journal of Applied Psychology. Vol. 2, No. 6, 2013, pp. 68-74. doi: 10.11648/j.ajap.20130206.11

\begin{abstract}
Theoretical work on marital conflicts suggests that perception plays a crucial role in influencing spouses' attitude towards marital conflict. However, relatively little research exists on psychological factors influencing spousal perception of marital conflicts. This study investigated spousal perception of marital conflict among Ghanaian dual career couples through the perceptual lens of personal values. Using dual career couples as the target population, 88 respondents answered questionnaire that consisted of the 21 Portrait Value Questionnaire designed to measure four value orientations, and the Spousal Perception of Marital Conflict Scale. Two hypotheses were formulated to test the relationships between the value orientations and spousal perception of marital conflict. Data was analyzed using hierarchical and standard multiple regression methods. Contrary to expectations, none of the hypothesis was supported. However, the study revealed that values such as openness to change, conservation and self-enhancement positively influenced spousal perception of marital conflict. These have implications for marital interactions and the development of interventions for couples dealing with marital conflicts.
\end{abstract}

Keywords: Personal Values, Dual Career Couples, Openness to Change, Self-Enhancement, Self-Transcendence, Conservation

\section{Introduction}

Marriage has been described as the most important and fundamental human relationship because it provides the primary structure through which families are established and the rearing of the next generation is accomplished (Esere, Yusuf \& Omotosho, 2011). It has also been identified it as a social necessity and an essential phenomenon in human life irrespective of tribe, society and religious affiliations because it also serves as a moral safeguard for the legitimate expression of sexual needs of people by regulating their sexual behaviors in such a way as to prevent them from becoming slaves to it (Esere et al., 2011). Marriage is therefore held in such high esteem by people because of its perceived relationship with a meaningful, rich life and this is characterized by the desire of the unmarried to join the marriage wagon and also the excitement that greets most marriage announcements. In the Ghanaian society, marriage plays such a significant role both socially and culturally, that, individuals who do not get married after a certain age, experience either overt or subtle pressure from friends and family members to do so as early as possible. Yet, while marriage seems to be a highly desirable relationship, Angel 2008, describe it as the most difficult maze one could ever get lost in and depending on what one makes of it, marriage can equal either bliss or chains. Several studies also indicate that marital satisfaction is not easily achieved because it does not always experience the "live happily ever after" syndrome that characterizes most fairy love tales as well as romantic novels and movies. A lot of marriages go through trauma, distress, separations and other equally unpleasant experiences that sometimes live either a partner or both partners emotionally and psychologically scarred if not 
physically as well (Osarenren, Nwadinigwe \& Anyama, 2013). Among the many causes of marital distress and marital disruptions that the literature on marriage has identified is the issue of marital conflict.

\section{History}

\subsection{Marital Conflicts}

In Ghana and elsewhere, the national dailies and media houses are replete with news about couples experiencing marital conflicts. Data from FIDA-Ghana and the Department of Social Welfare suggest that marital conflict is on the increase in the country. This trend is worrying especially when considered in the light of several research findings that have confirmed the phenomenon as having serious mental health and social implications (Esere et al., 2011; Osarenren et al., 2013; Tam, Lee, Foo \& Lim, 2011).

According to Sotonade (1998), disagreements in the marital relationship becomes a conflict when it goes beyond the normal intellectual difference that characterizes marital relationship to the emotional realm involving feelings of anxiety or anger and sometimes followed by abusive languages and hostile actions. Beuhler et al. (as cited by Tam \& Lim, 2008) define marital conflict as the existence of high levels of disagreements, stressful and hostile interactions between spouses, disrespect and verbal abuse while Cummings (as cited by Tam \& Lim, 2008) interprets it as "any major or minor interpersonal interaction that involved a difference of opinion, whether it was mostly negative or even mostly positive." According to Cummings (as cited by Tam \& Lim, 2008), everyday marital conflict refers to daily interactions, whether major or minor, in which couples have a difference of opinion. Thus, everyday marital conflict includes a range of tactical and emotional expressions, both positive and negative with marital aggression being on the negative extreme of a continuum of marital conflict which includes varying degrees of violent behaviors, comprising of both verbal and physical acts.

Because every individual is unique every marital relationship is also as unique as the individuals it contains and their relational abilities are very influential to their marital outcomes. Osarenren et al., (2013), duly noted that marriage is an adventure because the two individuals involved have agreed to cohabit willingly, to take risks, test new ideas and experience new situations and that no matter how long the courtship will be, neither can boast of having studied and known all about the partner's idiosyncrasies. Hence, differences and difficulties are inevitable in marriages and some degree of conflict is bound to be experienced (Tam \& Lim, (2008).

Conflicts have been associated with negative tendencies such as bitterness, disruption of relationships, poor mental health and sometimes violence (Tam et al., 2011). Conflicts have also been known to greatly improve the lives of people by challenging their potential and abilities, making them innovative, more open-minded, and generally improving their interpersonal and communication skills Osarenren et al., 2013). Several researchers have established that it is not necessarily what happens in the marriage, but how the partners perceive and define what has happened that is critical (Esere, 2008,; Esere et al., 2011). Perception therefore plays a major role in influencing, understanding and defining conflicts in marriage. There are several factors such as gender, culture, values, experience, personality and race that influence the process of perception such that in a conflict situation, what is actually meant if not communicated appropriately, sometimes eventually gets lost in a firestorm of responses to perceived wrongs (Idowu \& Esere, 2007). Conflict could therefore be interpreted as either positive or negative depending on the parties involved. Our different backgrounds also influence how we value and perceive substantive, procedural and psychological needs which subsequently tend to influence our willingness to engage in various conflict behaviors.

\subsection{Dual Career Couples and Marital Conflicts}

The emergence of dual career couples is becoming an increasingly common feature in the Ghanaian society. It is a recent phenomenon that has been observed in other countries as well and is attracting a lot of attention among researchers (Rusconi \& Solga, 2008). It is currently one of the most significant social transformations taking place in our societies today because of its implications for gender issues, changing roles and value systems. Education and changing gender roles have led to the entry of women into areas that traditionally were the preserve of men and this carries in its wake changing value systems that have implications for marital conflicts. The empowerment of women, socially and economically as well as the awareness creation about gender issues are posing challenges to existing and time-tested traditional gender concepts which are value-bound (Atta, Adil, Shujja \& Shakir, 2013).

Currently, there is the growing assumption among some Ghanaians that the entry of women into careers that were traditionally occupied by men, the increasing activities of feminist groups and other related changing gender roles may influence the value systems of men and women. Over the years, the Ghanaian media have also carried stories, reports, discussions and programs about career women who have abandoned tradition and are seeking for equality with their husbands on issues related to factors such as lifestyle, marital power, decision making, property ownership and household chores. Career women on such programs have been portrayed as being the cause of most of the conflicts in their marriages because they are perceived to be arrogant, disrespectful, opinionated, and generally lacking total appreciation for traditional and cultural values pertaining to the roles of husbands and wives. There is also the assumption that dual career couples experience a lot of conflicts and do not usually have good marriages because career women tend to have values that are incompatible 
with what is expected of a wife in marriage. These assumptions, fuelled by the stereotypes and prejudices associated with the male and female genders and the values that go with them are likely to have diverse implications for conflicts in marital relationships.

\subsection{Personal Values}

Personal values are an individual's unique conception or personal knowledge of the appropriate values for their own genes, feelings and experience (Santrock, 2007). Values are defined as desirable, trans-situational concepts or beliefs concerning goals (Schwartz, 2007). These goals vary in their importance as guiding principles in people's lives. They summarize a wide range of potential characteristics and generally motivate behavior because, once a value is internalized, it consciously or unconsciously becomes a standard criterion for guiding action. Values influence people in terms of their thoughts, feelings and actions as well as what they want and consider important in their lives. Values are also imbedded in the different roles men and women play in society and these tend to influence their behaviors. According to the value theory, people will necessarily behave according to their values because there of the need for consistency between their beliefs (values) and actions (Schwartz, 2007). Also, value-consistent action is rewarding as it helps people attain satisfaction from this action.

\subsection{The Four Cultural Dimensions of Personal Values}

Schwartz (2007) describes a typology of different value contents by reasoning that values represent three universal requirements of human existence: meeting the biological needs of the individual, the essential coordination of social interaction, and the survival of the group and the satisfaction of their interests. Ten basic values postulated to be important in societal functioning were determined on this basis: power, achievement, hedonism, stimulation, selfdirection, universalism, benevolence, tradition, conformity, and security. These ten basic human values have proved to be universally recognized by all cultures and that leaves out no major value that is meaningful across societies (Biber, Hupfeld \& Meier, 2008).

According to Schwartz (2007), the ten value types also represent four cultural dimensions which are selfenhancement, self-transcendence, openness to change and conservatism. A dynamic relationship exists between the value types and this is evidenced in the structure of the values which is expressed in two orthogonal dimensions. The first dimension puts self-enhancement and selftranscendence at opposite ends, and the types of values that lie along this dimension are power and achievement, which primarily emphasize pursuit of one's own interests, as opposed to universalism and benevolence, the types of values that are interested in the welfare and interests of others. The second dimension puts openness to change in opposition to conservation, and the types of values along this dimension are self-direction and stimulation (independent action, thought, and feelings, readiness for new experiences) in opposition to security, conformity, and tradition types of values (self-restraint, order, resistance to change). Hedonism contains both the elements of openness to change and elements of self-enhancement. Because of their emphasis on independent thought and action and their support for change, self-direction and stimulation conflict with conformity, tradition and security, which stress on submissive self-control, maintenance of traditions, and the protection of stability. Universalism and benevolence lie opposite to achievement and power, because the acceptance of others as equals and an interest in their welfare is in conflict with the assertion of oneself and the effort to dominate. Hedonism conflicts with conformity and tradition, because indulging in one's own wishes is irreconcilable with self-control and the acceptance of external restrictions

Actions that people take in pursuit of their values have been found to have psychological, practical and social consequences that are either compatible or conflict with the pursuit of other types of values (Biber et al., 2008). This observation is also supported by Asuquo and Maliki (2007) who argued that interpersonal conflicts are inevitable when people with incompatible values find themselves in an interdependent relationship. Societies typically socialize boys and girls to occupy different social roles and to affirm different life goals and sanction them for failing to do so (Liu, Yu, Cottrell, Lunn, Deveaux, Brathwaite, Marshall, Li $\&$ Stanton, 2007). Women are viewed as more relational, expressive, and communal, whilst men are viewed as more autonomous, instrumental, and agentic. These dissimilarities in men's and women's motives and orientations are likely to find expression as different value priorities. According to Liu et al. (2007), men usually attribute importance to power values in particular and also to achievement, hedonism, stimulation and self-direction values more than women. Women on the other hand, attribute more importance especially to benevolence values and also to universalism, conformity, and security values than men. This basically means that men and women will not appreciate or perceive things in the same manner and this situation is likely to create fertile grounds for conflicts in marriage.

Studies have confirmed that there are differences in the values of men and women (Liu et al., 2007). It has been found that men emphasize agentic-instumental and selfenhancement values such as power and achievement whilst women emphasize expressive-communal and selftranscendence values such as benevolence and universalism (Liu et al., 2007). The Ghanaian society is largely patriarchal and traditional customs, folklores, songs, proverbs and the general culture espouse certain core values that guide the behavior of men and women that extends even into the arena of marriage. Since individual or gender differences in value priorities have been found to influence actual behaviors such as pro-social, antisocial, 
environmental, political, consumer, and delinquent behaviors it is possible that spousal perception of marital conflict could be equally influenced.

\subsection{Rationale for the Study}

Most of the studies conducted on marital conflict have focused on the causes and management of the conflicts and its implications for marital outcomes (Angel, 2008; Esere et al., 2011; Idowu \& Esere, 2007). Others have also focused on what spouses do when there is conflict (Esere et al., 2011; Osarenren, 2013). It has however been observed that in spite of the research based interventions that have been developed to help spouses deal with conflict, many spouses continue to experience distress because of their aversive and ineffectual response to conflict. Considering the physical and psychological implications of marital conflicts on couples, it is important that in order to deepen understanding on how conflict is experienced by individuals, more studies be conducted on other factors such as the psychological processes involved in the conflict process (Tam et al., 2011).

\subsection{Objectives}

Several studies (Liu et al., 2007; Biber et al, 2008) have indicated the critical role that personal values play in determining the behavior of people in virtually every aspect of their lives. Having opposing value orientations in an interdependent relationship have also been found to lead to interpersonal conflicts. However, relatively little information exists on how these value interactions influence spousal perception of marital conflict. The purpose of this study therefore is to examine whether personal values have any influence on spousal perception of marital conflict among dual career couples. Specifically, this study will examine whether the four value orientations, namely; openness to change, conservation, self enhancement, and self transcendence will have any influence on spousal perception of marital conflicts among Ghanaian dual career couples.

\subsection{Hypotheses}

Several studies indicate the critical role that personal values play in determining the behavior of people in virtually every aspect of their lives (Liu et al., 2007). It has also been established that people in interdependent relationships experience more interpersonal conflicts the more opposed their value orientations are. In investigating the dynamic interactions of these values in relation to spousal perception of marital conflict, this study examined two main hypotheses.

Hypothesis 1: Spouses whose personal values express openness to change will have a more positive perception of marital conflict than those whose values express conservation.

Hypothesis 2: Spouses whose values express selfenhancement are more likely to perceive marital conflict negatively than those spouses whose values express selftranscendence.

\section{Methods}

The targeted population for the study was all dual career couples within the Greater Accra Region. Even though dual career couples are likely to be found in all the ten regions of Ghana, the Greater Accra Region was selected primarily by virtue of it being the capital town of Ghana and hence more likely to be inhabited by people who hail from all over the ten regions. Secondly, the Greater Accra Region has a greater number of institutions and organizations in which career people can be found.

\subsection{Sample Profile}

Table 1. Sample Characteristics of Respondents

\begin{tabular}{|c|c|c|}
\hline Variables & Frequency & Percentage \\
\hline \multicolumn{3}{|l|}{ Age of husbands: } \\
\hline $25-34$ & 4 & 4.5 \\
\hline $35-44$ & 28 & 31.8 \\
\hline $45-54$ & 11 & 12.5 \\
\hline $55-64$ & 1 & 1.1 \\
\hline \multicolumn{3}{|l|}{ Age of wives: } \\
\hline $18-24$ & 2 & 2.3 \\
\hline $25-34$ & 10 & 11.4 \\
\hline $35-44$ & 30 & 34.1 \\
\hline $45-54$ & 2 & 2.3 \\
\hline \multicolumn{3}{|c|}{ Level of education (Husbands): } \\
\hline First degree & 15 & 17.0 \\
\hline Masters degree & 27 & 30.7 \\
\hline Doctorate degree & 2 & 2.3 \\
\hline \multicolumn{3}{|c|}{ Level of education (Wives): } \\
\hline HND & 8 & 9.1 \\
\hline First degree & 18 & 20.5 \\
\hline Masters degree & 15 & 17.0 \\
\hline ACCA/Diploma & 3 & 3.4 \\
\hline \multicolumn{3}{|c|}{ Number of Years of Marriage: } \\
\hline $0-5 \mathrm{yrs}$ & 26 & 29.5 \\
\hline $6-10 y r s$ & 27 & 30.7 \\
\hline $11-15 y r s$ & 22 & 25.0 \\
\hline $16-20 \mathrm{yrs}$ & 11 & 12.5 \\
\hline $21-25 y r s$ & 2 & 2.3 \\
\hline
\end{tabular}

Convenience sampling technique was used to select some institutions and organizations within the Greater Accra Region from which a total number of 88 respondents, made up of 44 dual-career couples in a heterosexual marriage which has been contracted customarily, legally or by ordinance were purposively selected. Respondents' ages ranged from 25 to 64 . As indicated in Table 1, the highest percentages of $31.8 \%$ and $34.1 \%$ for husbands and wives respectively, represents the age range of 35 to 44 years. $30.7 \%$ of respondents recorded the highest frequency of 27 , 
representing the number of couples who had been married for periods ranging between 6 to 10 years. $30.7 \%$ of husbands had obtained a masters degree as compared to $17 \%$ of wives who had also obtained the master's degree.

A simple descriptive correlational research design was employed in this study. An adaptation of the 21 item Portrait Values Questionnaire developed by Schwartz, Melech, Lehmann, Burgess, Harris \& Owens (2001), and the Spousal Perception of Conflict Scale (an adaptation from the Children's Perception of Interparental Conflict Scale (CPIC) developed by Grych, Seid \& Fincham, 1992) were used in this study.

\section{Results and Discussions}

Contrary to the expectation of this study, the prediction that "Spouses whose personal values express openness to change will have a more positive perception of marital conflict than those whose values express conservation" was not supported. Both spouses expressed positive perception of marital conflict given the differences in values. The results as expressed in table 2 indicated that spouses with openness to change value $(\beta=.09, \mathrm{p}>.05)$ did not differ from those with value of conservation $(\beta=.09, \mathrm{p}>.05)$. Openness to change accounted for $1 \%$ of the variance while conservation also accounted for $1 \%$ of the variance in perception of marital conflict. However, each of this variance was not significant in predicting spousal perception of marital conflict.

Table 2. Hierarchical multiple regression of the effect of conservation, openness to change, self-enhancement and self-transcendence

\begin{tabular}{|c|c|c|c|c|}
\hline Model & & b & SE $\beta$ & $\boldsymbol{\beta}$ \\
\hline \multicolumn{5}{|l|}{ Step 1} \\
\hline & (Constant) & 44.40 & 2.32 & \\
\hline & Openness to change & .12 & .15 & .09 \\
\hline \multicolumn{5}{|l|}{ Step 2} \\
\hline & (Constant) & 43.86 & 2.47 & \\
\hline & Openness to change & .06 & .17 & .05 \\
\hline & Conservation & .11 & .16 & .09 \\
\hline \multicolumn{5}{|l|}{ Step 3} \\
\hline & (Constant) & 43.71 & 2.79 & \\
\hline & Openness to change & .06 & .18 & .04 \\
\hline & Conservation & .10 & .16 & .08 \\
\hline & Self-enhancement & .03 & .21 & .01 \\
\hline \multicolumn{5}{|l|}{ Step 4} \\
\hline & (Constant) & 43.85 & 2.77 & \\
\hline & Openness to change & .11 & .19 & .08 \\
\hline & Conservation & .33 & .22 & .26 \\
\hline & Self-enhancement & .01 & .21 & .00 \\
\hline & Self - transcendence & -.36 & .23 & -.26 \\
\hline
\end{tabular}

$\mathrm{R} 2=.01,0.1, .01$, and .04 for step $1,2,3$, and 4 respectively; $\Delta \mathrm{R} 2=.01, .01, .00$ and .03 for step $1,2,3$, and 4 respectively

According to the theory proposed by Schwartz, (2007), attributing an extremely high priority to a value induces overly intense and rigid pursuit of that value. Thus people who value openness to change are more likely to pursue or to emphasize their own independent thoughts and experience risk taking and adventure in contrast to people who attribute little importance to that value. On the other hand, people who highly rate conservatism may seek to preserve traditional practices, and protect stability thus making them less likely to engage in problem behaviors. Asuquo and Maliki (2007) also indicated in their study, that poor congruency between spouses in terms of their values orientation, can mean disharmony, dissatisfaction and mutual maladjustment, leading to tension, bitterness, frustration and conflict between marital partners - which may ultimately result in separation or divorce.

In view of the dynamism associated with the interaction among the various value types, several factors could have accounted for the rejection of the hypothesis. Based on the fact that this study did not compare the values of the individuals that make up a couple, it is possible that couples in each of the two categories had compatible values. Openness to change comprises of values related to independence in thought, sensation seeking, adventure and novelty which predisposes an individual to embrace new phenomena. Thus it is possible that because of their orientation, spouses whose values expressed openness to change were ready to embrace new ideas and adopt attitudes that enabled them to develop a positive perception of marital conflict. It is even likely that people who prioritize these values even perceive conflict situations as a stimulating encounter that satisfies their quest for sensation seeking and adventure. On the other hand, conservation comprises of values related to the maintenance of tradition and culture including religion. Thus spouses whose values expressed conservation may have also adopted attitudes and behaviors that helped them to develop a positive perception of marital conflict in order to maintain the stability of their marital relationships.

Secondly, people's age, education, gender, and other characteristics largely determine the life circumstances to which they are exposed. These include their socialization and learning experiences, the social roles they play, the expectations and sanctions they encounter, and the abilities they develop. Thus, differences in background characteristics represent differences in the life circumstances that affect value priorities and these factors have been found to influence marital conflicts (Zainah, Nasir, Ruzy \& Noraini, 2012). Most of the respondents in this study were above the age of thirty and it is therefore possible, that irrespective of their value orientations, respondents' positive perception of marital conflict could have been influenced in a way by their ages as well as other demographic variables. This assumption is based on research findings which noted that younger couples tend to experience conflicts more than older couples, which gives an indication that maturity and experience influenced the importance attached to conflict-related issues. According to Zainah et al., (2012), couples who had been married for an 
average period of ten years or more tended to experience increased marital satisfaction and less conflict. Also the experience of being in a dual-career marriage where strict gender expectations are difficult to meet as well as the challenges of juggling the many roles that the couples play, may have created the opportunity for them to adapt their values by upgrading the importance they attribute to the benefits associated with conflicts.

Finally, another probable explanation for the rejection of the hypothesis may be due to the influence of the culture of collectivism that is predominant in Ghana as opposed to the individualistic cultures where the Portrait Value Questionnaire (PVQ) has been extensively used. It is assumed in many Ghanaian societies that one does not marry just an individual in the family but the whole family as well hence there is the possibility of always assessing social support in dealing with marital difficulties such as conflicts. Thus, irrespective of the influence of foreign culture and other changing trends that might influence people's values, the deeply ingrained Ghanaian cultural values in relation to marital interactions may have prevailed hence influencing most of the respondents' perception of marital conflict.

Interestingly enough, the hypothesis which states that "Spouses whose values express self-enhancement are more likely to perceive marital conflict negatively than those spouses whose values express self-transcendence" was not supported in this study. Spouses with self-enhancing values $(\beta=.00, p>.05)$ rather perceived marital conflict positively while those with self-transcendence $(\beta=-.26, p>.05)$ perceived marital conflict negatively. Self-enhancing value did not account for a variance in spousal perception of marital conflict while value of self-transcendence accounted for $3 \%$.

One would naturally assume, that based on the widely accepted notion that conflict is inevitable in marital relationships, spouses whose values express self transcendence and who place emphasis on acceptance of others as equals and an interest in their welfare, would have a more positive perception of marital conflict. It is therefore surprising that contrary to expectations, spouses whose values reflect self-enhancement and stress on assertion of oneself and the effort to dominate rather perceived marital conflict positively. This trend may however be probably due to the enlightenment of respondents as a result of their educational background as well as by virtue of their being probably more egalitarian in their views of gender relations which have been found to be major contributors of marital conflicts.

One other major observation that could also explain the rejection of the hypothesis is based on the data which indicated that those whose values expressed selftranscendence were mostly females and those whose values expressed self-enhancement were mostly males. Because societies hold different expectations regarding gender in terms of social status and roles, males and females are usually socialized to attain different values and to occupy different social roles. Liu et al. (2007) found that males emphasized self-enhancement values which comprise values like power and achievement while females also emphasized self-transcendence values comprising of values like universalism and benevolence. Women have been described by some as relationship 'architects' because they tend to be more nurturing and more affiliated with others than men who tend to be autonomous and more individuated (Liu et al., 2007). According to some researchers, when pursuance of values such as those concerning material well-being (power) and security are blocked, their importance increases and when they are easily attained their importance drops (Bartkowski \& Xiaohe, 2010). Females have been found to express a negative perception of marital conflict especially where their expectations remain largely unfulfilled. They have also been found to initiate conflict relations especially with regards to issues related to power, gender inequalities, decision-making and division of house-chores which have been identified by the marriage literature as being some of the causes of marital conflict (Esere et al., 2011; Osarenren et al., 2013; Tam et al., 2011)). This trend could therefore have accounted for the findings observed.

\section{Conclusion}

The issue of marital conflict has received much attention from researchers because of the critical role it plays in the determination of marital outcomes. The extant literature on the subject has also revealed the causes of conflict as well as the techniques for managing them. In spite of the many interventions available to couples to deal with marital conflicts, many marriages continue to suffer the plagues associated with it hence creating the need to study other processes involved in the conflict interaction. This study therefore provided a unique opportunity to study the influence of personal values on spousal perception of marital conflict. The study was also targeted at dual-career couples which is becoming a growing phenomenon in Ghana. Although none of the hypothesis was supported, the results of the study indicate that with the exception of values that expressed self-transcendence, all the other values were related to a positive perception of marital conflict. This implies that value orientations relating to openness to change, conservation and self-enhancement might have a positive influence on dual career couples' perception and consequent relational abilities thus reducing the negative impact of conflicts on their relationships. On the other hand, spouses who express values relating to selftranscendence could experience a more negative impact of marital conflicts because of their negative perception of it. Couples in this category therefore could be appropriately counseled to deal more effectively with their marital conflicts.

The findings in this study also raise issues for further investigations on the subject matter. As a result of the social and economic empowerment of women as well as 
changing gender roles in a typical traditional and patriarchal country like Ghana, there are serious implications for the development of personal values of both men and women because of the influence of gender socialization. Further studies on the subject therefore will not only enable a deeper understanding of the influence of personal values on marital conflicts, but also, the likely implications of the outcomes of such investigations.

This study thus provides additional useful information that could be used as a base for further studies on the subject or for the development of some interventions that could help couples dealing with marital conflicts. Future researchers could also consider using the variables investigated in this study with dual-earner couples, couples with one income earner as well as the uneducated folks in the Ghanaian setting.

\section{References}

[1] Angel, U. (2008). Mastering interpersonal communication skills between you and your spouse. New York: Sage Publications Inc.

[2] Asuquo, P. N. \& Maliki, A. E. (2007). Values Orientation and Marital Conflict Resolution: Implication for Marriage Counselling. Stud. Tribes Tribals, 5(1):59-63.

[3] Atta, M., Adil, A., Shujja, S. \& Shakir, S. (2013). Role of trust in marital satisfaction among single and dual career couples. International Journal of Research Studies in Psychology, Vol 2, No. 4, 53-62

[4] Bartkowski, J. P. \& Xiaohe X. (2010) Refashioning Family in the Twenty-first Century: Marriage and Cohabitation among America's Young Adults: The Changing Spirituality of Emerging Adults Project. Life Cycle Institute, Catholic University of America. Available on http://changingsea.org/ bartkowski.htm

[5] Biber, P., Hupfeld, J., \& Meier, L. L. (2008). Personal values and relational models. European Journal of Personality, 22:609-628.

[6] Esere, M. O. (2008). Communication in marriage relationship. In L. A. Yahaya, M.O. Esere, J. O. Ogunsanmi, \& A. O. Oniye (2008). Marriage, sex and family counselling. Ilorin: Unilorin Press Ltd.

[7] Esere, M. O., Yusuf, J., Omotosho, J. A. (2011). Influence of spousal communication on marital stability: Implication for conducive home environment. Edo Journal of counseling , 4 (1\&2), 50-61
[8] Grych, J. H., Seid, M., \& Fincham, F. D. (1992). Assessing marital conflict from the child's perspective: The Children's Perception of Interparental Conflict Scale. Child Development, 63,558-572

[9] Idowu, A. I. \& Esere, M. O. (2007). Communication in counselling: A multidimensional perspective. Ilorin: Tim Sal Publishers.

[10] Liu, H., Yu, S., Cottrell, L., Lunn, S., Deveaux, L., Brathwaite, N. V., Marshall, S., Li, X., \& Stanton, B. (2007). Personal values and involvement in problem behaviors among Bahamian early adolescents: A cross-sectional study. Available on (http://creativecommons.org/licenses/by/2.0),

[11] Osarenren, N., Nwadinigwe, P., Anyama, S. (2013). The impact of marital conflicts on the psychosocial adjustment of adolescents in Lagos Metropolis, Nigeria. Journal of Emerging Trends in Educational Research and Policy Studies (JETERAPS) 4 (2), 320-326

[12] Rusconi A, Solga H (2008). A systematic reflection upon dual career couples. Discussion Paper, Social Science Research Center Berlin (WZB), Berlin Lessons learned from the European social survey (pp. 167-201). London: Sage.

[13] Santrock, J.W. (2007). A Topical Approach to Life-Span Development. New York, NY: McGraw-Hill

[14] Schwartz, S. H. (2007). Value orientations: Measurement, antecedents, and consequences across nations. In R. Jowell, C. Roberts, R. Fitzgerald, \& G. Eva (Eds.), Measuring attitudes cross nationally.

[15] Schwartz, S. H., Melech, G., Lehmann, A., Burgess, S., Harris, M., Owens, V. E. (2001). Extending the crosscultural validity of the theory of basic human values with a different method of measurement. Journal of CrossCultural Psychology, 32(5), 519-542.

[16] Sotonade, O.A.T. (1998). Comparative effectiveness of two therapeutic skills in the resolution of marital conflict among selected couples in Ijebu-Ode. Ogun State. Unpublished doctoral dissertation. University of Ibadan.

[17] Tam, C. L., \& Lim, S. G. (2008). A study on measures of social support and mental health. Sunway academic Journal, $5,97-110$

[18] Tam, C. L., Lee, T. H., Foo, Y. C., \& Lim, Y. M. (2011). Communication skills, conflict tactics and mental health: A study of married and cohabitating couples in Malaysia. Asian Social Science, 7 (6), 79-87

[19] Zainah, A. Z., Nasir, R., Ruzy, S. H. \& Noraini M. Y., (2012). Effects of demographic variables on marital satisfaction. Asian Social Science. Vol. 8, No. 9, 46-49. 